\title{
PENGHORMATAN PRINSIP-PRINSIP KEMANUSIAAN TERHADAP TAWANAN PERANG DALAM KONFLIK BERSENJATA MENURUT KONVENSI JENEWA III TAHUN 1949 (Studi Kasus Penyiksaan Tawanan Perang AS Di Penjara Guantanamo)
}

\author{
D A N I A L \\ Fakultas Hukum Universitas Sultan Ageng Tirtayasa \\ E_Mail: bontobangun@gmail.com
}

\begin{abstract}
Humanitarian principle aims to protect and ensure respect for the human. This research uses a normative, and the research also applies a descriptive-analytical approach to examine and analyse the research questions of the thesis. In doing so, this research uses a secondary data. These legal materials are subsequently analysed using a qualitative juridical approach. The results showed that the First, the concept of legal protection of prisoners of war under the Geneva Convention III 1949 indicates that the combatants who have the status of 'hors de combat' must be protected and respected in all circumstances. Tribute in the form of an obligation not to commit acts harmful, do not aggravate the situation, and do not kill people who are protected. Penahanpun state obligation to prevent harm and damage; Second, implementation of the Geneva Convention III 1949 against US prisoners of war in Guantanamo is not optimal. This happens because of differences in the interpretation of the Articles in International Humanitarian Law so as to cause the indication practices inhumane treatment, no legal protection, not considered welfare and not related to the outside world at Guantanamo will be undertaken by the US military guards.
\end{abstract}

Keywords: Respect, Humanity, Prisoner of War, Armed Conflict, Guantanamo

\begin{abstract}
Abstrak
Prinsip kemanusian bertujuan untuk melindungi dan menjamin penghormatan terhadap manusia. Penelitian ini menggunakan metode yuridis normatif dan bersifat deskriptif analitis, yaitu menganalisis identifikasi masalah dengan menggunakan data sekunder, kemudian dianalisis secara yuridis kualitatif. Hasil penelitian menunjukkan bahwa: Pertama, Konsep perlindungan hukum terhadap tawanan perang dalam Konvensi Jenewa III tahun 1949 menunjukkan bahwa kombatan yang telah berstatus 'Hors de combat' harus dilindungi dan dihormati dalam segala keadaan. Penghormatan berupa kewajiban untuk tidak melakukan tindakan-tindakan yang membahayakan, tidak memperparah keadaan, dan tidak membunuh orang yang dilindungi. Negara penahanpun berkewajiban untuk mencegah bahaya dan kerusakan; Kedua, Implementasi Konvensi Jenewa III Tahun 1949 terhadap tawanan perang Amerika Serikat di penjara Guantanamo belum optimal. Hal tersebut terjadi karena adanya perbedaan penafsiran terhadap Pasal-Pasal dalam Hukum Humaniter Internasional sehingga berakibat adanya indikasi praktek-praktek perlakuan tidak manusiawi, tidak mendapat perlindungan hukum, tidak diperhatikan kesejahteraannya dan tidak berhubungan dengan dunia luar di Penjara Guantanamo yang di lakukan oleh sipir militer Amerika Serikat.
\end{abstract}

Kata Kunci: Penghormatan, Kemanusiaan, Tawanan Perang, Konflik Bersenjata, Guantanamo

\section{PENDAHULUAN}

Prinsip kemanusian sebagai salah satu

prinsip dasar dalam hukum humaniter internasio- nal, dimaksudkan dalam memberikan bantuan tanpa diskriminasi kepada orang yang terluka di medan perang, berupaya dengan kapasitas inter- 
nasional dan nasional untuk mengurangi penderitaan manusia dimanapun ditemukan. Prinsip ini. Selain itu, Prinsip ini bermanfaat untuk meningkatkan saling pengertian, persahabatan, kerjasama dan perdamaian yang berkelanjutan diantara semua rakyat sehingga tidak menciptakan diskriminasi karena kebangsaan, ras, kepercayaan agama, pendapat kelas atau politik. Sebagai prinsip dasar hukum humaniter internasional, para pihak yang bersengketa diharuskan untuk memperhatikan perikemanusiaan, di mana mereka dilarang untuk menggunakan kekerasan yang dapat menimbulkan luka yang berlebihan atau penderitaan yang tidak perlu termasuk kepada tawanan perang.

Tawanan perang diatur dalam Konvensi Jenewa III tahun 1949, pada Pasal 12 Konvensi Jenewa III tahun 1949 mendefenisikan tawanan perang sebagai tawanan musuh, bukan tawanan orang-perorangan atau kesatuan-kesatuan militer yang telah menawan mereka. Lepas dari tanggung jawab perorangan yang mungkin ada, Negara penahan bertanggung jawab atas perlakuan yang diberikan kepada mereka. Dalam hukum humaniter internasional $(\mathrm{HHI})$, ada dua kelompok komunitas yang dapat dikategorikan sebagai tawanan perang, yaitu: Pertama, tentara regular. Tentara regular (yang memenuhi syarat-syarat yang telah ditetapkan oleh $\mathrm{HHI}$ seperti menghormati hukum-hukum dan kebiasaan-kebiasaan perang) dapat menikmati jaminan hukum yang ditetapkan bagi tawanan perang pada saat meninggalkan peperangan dengan cara terpaksa seperti karena cedera, atau karena keinginannya sendiri dengan cara membuang senjata. Kriteria ini juga diberikan bagi angkatan perang regular yang tunduk pada suatu pemerintahan atau kekuasaan yang tidak diakui oleh negara yang menahan. ${ }^{1}$

Pasal 4 ayat 2 Konvensi Jenewa III tahun 1949 juga memberikan status tawanan perang terhadap anggota-anggota milisi serta anggotaanggota dari barisan sukarela lainnya yang beroperasi di dalam atau di luar wilayahnya sendiri, sekalipun wilayah itu diduduki, selama mereka memenuhi syarat-syarat yang terdapat dalam Pasal 1Piagam Den Haag tahun 1907, yaitu:

a. Prajurit tersebut berada di bawah komando seorang yang bertanggungjawab terhadap bawahannya.

b. Mereka memiliki tanda pengenal yang tetap dan dapat dikenal dari kejauhan.

c. Membawa senjata mereka secara terangterangan

d. Dalam melaksanakan operasi militer patuh terhadap hukum-hukum dan kebiasaankebiasaan perang

Demikian halnya Pasal 4 ayat 6 Konvensi Jenewa III tahun 1949 juga memberikan status tawanan perang terhadap penduduk suatu wilayah yang belum jatuh dalam pendudukan yang, ketika musuh mendekat, mereka bangkit melakukan perlawanan terhadap pasukan-pasukan yang menyerang, asal saja mereka membawa senjata secara terang-terangan dan menghormati hukum-hukum dan kebiasaan-kebiasaan perang.

Kedua, kelompok lain yang dikategorikan sebagai tawanan perang dalam Pasal 4 ayat 4 Konvensi Jenewa III tahun 1949 adalah kelompok 
yang dikategorikan sebagai tawanan perang tetapi bukan tentara regular meliputi orang-orang sipil yang menyertai angkatan perang yang mencakup: para pemasok perbekalan (logistic perang), anggota unit kerja yang bertanggungjawab atas kesejahteraan dan kenyamanan angkatan perang, orang-orang sipil yang menjadi awak pesawat terbang militer, wartawan atau koresponden perang, dengan syarat mereka dibekali surat-surat pengesahan dan identitas pribadi oleh angkatan perang yang mereka sertai.

Status tawanan perang pun diperluas oleh Pasal 44 Protokol Tambahan I. Protokol Tambahan I memperluas perlindungan yang diberikan kepada pemberontak, dan gerilyawan dengan memberikan mereka status tawanan perang seperti yang diatur dalam Konvensi Jenewa III. Alasan untuk melakukan hal itu adalah bahwa masalahnya tidak begitu banyak cara untuk mendapatkan status sebagai kombatan dan tawanan perang, namun bagaimana untuk menghindari agar status tersebut tidak hilang. Anggota kelompok bersenjata adalah tawanan perang kecuali mereka melakukan kejahatan perang, maka memungkinkan dituntut sebagai terorisme. Mereka tidak pernah bisa dituntut atas dasar hukum nasional karena mengangkat senjata, sebab mereka adalah kombatan. Namun, Kondisi tersebut menyebabkan pemberian status tawanan perang jadi lemah. Karena pada dasarnya pemberian status tawanan perang bertujuan untuk meningkatkan

2 Michla Pomerance, Self Determination in Law And Practice: The New Doctrine of the United Nations, The Hague/ Boston: M. Nijhoff, 1982, hlm. 53 perlindungan yang diberikan kepada kombatan dalam konflik bersenjata. ${ }^{2}$

Pasal 44 merupakan salah satu alasan Amerika Serikat belum meratifikasi Protokol Tambahan I. Amerika Serikat membagi kombatan menjadi dua yakni kombatan yang sah dan tidak sah, konsep tersebut jelas tidak ada dalam hukum humaniter. Ini adalah penafsiran hukum terhadap Protokol Tambahan I. Presiden Ronald Reagan merasa Protokol Tambahan I itu, dan khususnya Pasal 44, memberikan legitimasi bagi teroris dan juga kemungkinan membatasi hukuman bagi anggota kelompok bersenjata atas tindakan mereka. ${ }^{3}$ Konsekuensi dari keputusan Amerika adalah dibangunnya penjara Guantanamo yang diperuntukkan terhadap orang-orang yang diduga teroris. Walaupun masyarakat internasional menolak keputusan Amerika tersebut. Namun, Amerika Serikat tetap memaksakan membangun penjara Guantanamo yang kemudian di duga sebagai tempat penyiksaan para tawanan perang Amerika Serikat.

\section{RUMUSAN MASALAH}

Berangkat dari pemaparan di atas, dirumuskan masalah tersebut sebagai berikut: Pertama, Bagaimana konsep perlindungan hukum terhadap tawanan perang dalam Konvensi Jenewa III tahun 1949; Kedua, Bagaimana implementasi Konvensi Jene-wa III tahun 1949 terhadap tawanan perang Amerika Serikat di penjara Guantanamo.

3 Georges H. Aldrich, Prospects for United States Ratifi cation of Additional Protocol I to the 1949 Geneva Conventions, 1991, hlm. 85 


\section{METODE PENULISAN}

Penelitian ini menggunakan metode penelitian yuridis normatif, dengan pendekatan undangundang (statute approach), pendekatan kasus (case approach), dan pendekatan historis (histrorical approach). Jika dilihat dari sifatnya, penelitian ini dikategorikan sebagai penelitian deskriptif analitik. Yaitu mencari data atau gambaran seteliti mungkin mengenai objek dari permasalahan. Adapun tahap pengumpulan data ini dilakukan dalam dua tahap yaitu: (a) Penelitian kepustakaan yaitu pengumpulan data dilakukan melalui penelusuran terhadap bahan-bahan hukum primer berupa bahan hukum, bahan hukum sekunder dan bahan hukum tertier.

\section{PEMBAHASAN}

\section{Perlindungan Hukum Terhadap Tawanan Pe-} rang Menurut Konvensi Jenewa III tahun 1949

Salah satu hal mendasar dalam hukum humaniter Internasional adalah bahwa dalam konflik bersenjata, satu-satunya tindakan yang dapat diterima adalah melemahkan potensi militer musuh. Hal ini mensyaratkan bahwa hukum humaniter internasional memiliki potensi untuk mendefinisikan siapa yang dianggap sebagai kombatan dan yang karenanya dapat menyerang atau di serang dan berpartisipasi langsung dalam peperangan. Berdasarkan prinsip pembedaan, semua yang terlibat dalam konflik bersenjata harus membedakan antara orang-orang yang terlibat (Kombatan) dan penduduk sipil. ${ }^{4}$ Kombatan harus membedakan diri mereka sendiri (memungkinkan musuh-musuh mereka untuk mengidentifikasi me- reka) dari kelompok masyarakat lain (penduduk sipil), yang tidak terlibat atau tidak berpartisipasi langsung dalam peperangan.

Oleh karena itu, penduduk sipil yang terlibat dalam permusuhan, dianggap menjadi bagian dari kombatan, hal itu merupakan perubahan besar dalam konsep kombatan. Kombatan merupakan milik angkatan bersenjata menurut Pasal 4 Konvensi Jenewa III, Pasal 43 dan 44 Protokol Tambahan I. Ada perubahan besar dalam Protokol Tambahan I sejak dokumen tentang kriteria kombatan diatur dalam Pasal 4 Konvensi Jenewa III untuk memenuhi situasi baru dan keadaan yang disebabkan oleh perang untuk penentuan nasib sendiri. Masalah utama adalah bahwa beberapa negara belum meratifikasi Protokol Tambahan I. Selain itu, sifat perang yang berubah saat ini, terutama di era pergerakan terorisme.

Pada dasarnya tujuan dari Protokol Tambahan I adalah untuk memberi jawaban atas tantangan yang muncul dari perjuangan untuk menentukan nasib sendiri dan para pihak dalam konflik horisontal. Pasal 44 Protokol Tambahan I memberikan informasi tambahan mengenai kombatan dan tawanan perang. Ayat 2 Pasal 44 PT I menyatakan bahwa jika seorang kombatan melanggar aturan hukum internasional, ia tidak akan kehilangan statusnya sebagai kombatan atau sebagai tawanan perang, kecuali dalam keadaan dinyatakan dalam ayat 3 dan 4 . Ayat 3 mengingatkan kita bahwa kombatan harus membedakan dirinya setiap saat dari penduduk sipil. Bila hal ini tidak mungkin karena sifat permusuhan, kombatan akan tetap pada statusnya asalkan ia menam- 
pakkan diri setiap keterlibatan militer, dan ketika "dia terlihat musuh saat terlibat dalam penyebaran militer sebelum peluncuran serangan di mana ia berpartisipasi".

Selanjutnya ayat 4 mengatakan bahwa kombatan yang ditangkap dan tidak memenuhi kriteria di atas akan kehilangan haknya sebagai tawanan perang, tapi akan mendapatkan perlindungan setara dengan perlindungan diberikan oleh Konvensi Jenewa III dan Protokol Tambahan I untuk tawanan perang. Ayat 5 menyatakan bahwa jika kombatan ditangkap ketika ia tidak terlibat dalam serangan atau persiapan militer, ia tidak akan kehilangan statusnya sebagai kombatan atau tawanan perang. Jika seorang tentara berlibur bersama keluarganya kemudian tertangkap, dia akan mendapatkan status kombatan dan tawanan perang.

Perlindungan terhadap tawanan perang adalah hal yang sangat penting diperhatikan saat terjadinya konflik bersenjata, hal ini dimaksudkan untuk menghindari perlakuan yang tidak manusiawi. Dalam sengketa bersenjata, orang-orang yang dilindungi dapat dibagi atas dua golongan meliputi kombatan dan non kombatan (Penduduk sipil). Demikian halnya kombatan yang telah berstatus 'Hors de combat' 5 harus dilindungi dan dihormati dalam segala keadaan. Penghormatan pada dasarnya bersifat pasif, yaitu kewajiban untuk tidak melakukan tindakan-tindakan yang membahayakan, tidak memperparah keadaan, dan tidak membunuh orang yang dilindungi. Perlindungan yang dimaksud merupakan perlindungan yang bersifat aktif, berupa kewajiban untuk mencegah bahaya dan kerusakan.

Pada tahun 1474, misalnya, Pengadilan Internasional menjatuhkan hukuman mati kepada Peter Von Hagenbach, pelaku kekejaman saat pendudukan Breisach. Dalam perang saudara utara-selatan di Amerika, Abraham Lincoln juga melarang perilaku tidak manusiawi dan mengancam dengan pidana, termasuk pidana mati, terhadap para pelaku penyiksaan terhadap tawanan perang 6 .

Dua kodifikasi hukum Internasional yakni Konvensi Jenewa 1949 dan Instrumen pokok hakhak Asasi Manusia Internasional menandai titik awal kodifikasi hukum perlindungan perang pada zaman modern. Konferensi-konferensi itu membahas tentang perlindungan terhadap tawanan perang. Dalam Konvensi Jenewa, perlindungan terhadap tawanan perang diatur dalam konvensi Jenewa ke-III pada Pasal 13-nya mensyaratkan bahwa: "Tawanan perang harus diperlakukan dengan perikemanusiaan. Setiap perbuatan yang bertentangan dengan hukum, atau kelalaian negara penahan yang mengakibatkan kematian atau yang benar-benar membahayakan kesehatan tawanan perang yang berada di bawah pengawasannya, adalah dilarang dan harus dianggap sebagai pelanggaran berat dari konvensi ini. Tawanan perang terutama tidak boleh dijadikan obyek penggudungan jasmani, percobaan-percobaan kedokteran atau ilmiah dalam bentuk apapun juga

Arlina Permanasari et. Al, pengantar hukum humaniter, ICRC, Jakarta, 1999, HIm.163

6 Marcella Elwina S, Mengatur Kejahatan Perang, Tampa Penerbit, Karawang, 2004, HIm.2 
yang tidak dibenarkan oleh pengobatan kedokteran, kedokteran gigi atau kesehatan dari tawanan bersangkutan dan dilakukan demi kepentingannya. Tawanan juga harus selalu dilindungi, terutama terhadap tindakan-tindakan kekerasan dan ancaman-ancaman, dan terhadap penghinaan-penghinaan serta tontonan umum. tindakan-tindakan pembalasan terhadap tawanan perang juga dilarang".

Sedangkan dalam Instrumen pokok HakHak Asasi Manusia, walaupun tidak diatur secara spesifik tentang perlindungan terhadap tawanan perang, akan tetapi karena tawanan perang terkadang tidak luput dari segala bentuk penyiksaan dan perlakuan kejam yang tidak manusiawi, maka aturan dalam konvensi ini dapat diterapkan dalam hal perlindungan terhadap tawanan perang. Mengenai larangan segala bentuk penyiksaan terhadap tawanan diatur dalam konvensi menentang penyiksaan dan perlakuan atau penghukuman lain yang kejam, tidak manusiawi dan merendahkan martabat manusia, pada Pasal 11 yang berbunyi sebagai berikut: "Setiap negara pihak harus senantiasa mengawasi secara sistimatik peraturanperaturan tentang interogasi, interuksi, metode, kebiasaan-kebiasaan dan perturan untuk melakukan penahanan serta perlakuan terhadap orangorang yang ditangkap, ditahan atau dipenjara dalam setiap wilayah kewenangan hukumnya, dengan maksud untuk mencegah terjadinya kasus penyiksaan".

Jadi, konvensi-konvensi di atas mewajibkan setiap negara yang turut serta meratifikasi konvensi tersebut, agar menghindarkan diri dari segala bentuk penyiksaan dan mengawasi para aparat penegak hukum mulai dari introgasi hingga adanya putusan pengadilan. Hal ini dilakukan intuk mencegah segala bentuk penyiksaan terhadap tawanan perang demi penghormatan terhadap prinsip-prinsip kemanusiaan.

\section{Efektifitas Konvensi Jenewa III Tahun 1949 Terhadap Tawanan Perang Amerika Serikat Di Guantanamo .}

Pasal 12 Konvensi Jenewa III tahun 1949 menegaskan bahwa tawanan perang adalah tawanan Negara musuh, bukan tawanan orangperorangan atau kesatuan-kesatuan militer yang telah menawan mereka. Lepas dari tanggung jawab perseorangan yang mungkin ada, Negara Penahan bertanggung jawab atas perlakuan yang diberikan kepada mereka.

Selanjutnya Pada Pasal 13nya menerangkan bahwa tawanan perang harus diperlakukan dengan perikemanusiaan. Setiap perbuatan yang bertentangan dengan hukum, atau kelalaian Negara Penahan yang mengakibatkan kematian atau yang benar-benar membahayakan kesehatan tawanan perang yang berada di bawah pengawasannya, adalah dilarang dan harus dianggap sebagai pelanggaran berat dari Konvensi ini. Tawanan perang terutama tidak boleh dijadikan obyek pengudungan jasmani, percobaan-percobaan kedokteran atau ilmiah dalam bentuk apapun juga yang tidak dibenarkan oleh pengobatan kedokteran, kedokteran gigi atau kesehatan dari tawanan bersangkutan dan dilakukan demi kepentingannya. Tawanan perang juga harus selalu dilindungi, terutama terhadap tindakan-tindakan kekerasan atau ancaman-ancaman, dan terhadap penghinaan-penghinaan serta tontonan umum. 
Selanjutnya pada Pasal 29 Bab III tentang Kesehatan dan Pengamatan Kesehatan, yang berbunyi: Negara Penahan wajib mengambil segala tindakan kesehatan yang diperlukan untuk menjamin kebersihan serta kesehatan tempat tawanan dan untuk mencegah wabah-wabah menular. Bagi tawanan perang harus disediakan untuk dipakai siang dan malam tempat-tempat pemandian dan kakus yang memenuhi syaratsyarat kesehatan dan yang terus menerus dipelihara dalam keadaan bersih. Di tiap kamp tawanan dimana tawanan perang wanita ditampung, harus disediakan bagi mereka tempattempat pemandian dan kakus yang terpisah. Selanjutnya di samping tempat-tempat mandi yang tersedia dalam kamp tawanan, tawanan perang harus juga diberikan air dan sabun yang cukup untuk keperluan kamar kecil dan untuk mencuci pakaian pribadinya. Bagi mereka harus disediakan instalasi-instalasi, fasilitas-fasilitas dan waktu yang diperlukan untuk maksud itu

Jadi, pada dasarnya Konvensi Jenewa III 1949 mengatur masalah tawanan perang yang meliputi status tawanan perang, hak dan kewajiban tawanan perang serta perlindungan terhadap tawanan perang dan harta bendanya. Adapun hak-hak tawanan perang meliputi hak untuk diperlakukan secara manusiawi, hak mendapat perlindungan hukum, hak untuk diperhatikan kesejahteraannya dan hak untuk berhubungan dengan dunia luar.

Namun demikian, dalam beberapa kasus seperti yang terjadi di Penjara Guantanamo di wilayah Kuba, Amerika latin Tanggal 29 April 2004, televisi CBS Amerika menayangkan film

Lihat di http://mirajnews.com/id/artikel/feature/kejamnyasiksaan-tentara-amerika penyiksaan terhadap para tahanan Guantanamo dan Abu Ghraib, oleh tentara AS. Dalam film dan foto-foto yang kemudian ditayangkan itu terbukti bahwa para sipir militer AS secara brutal menyiksa fisik dan mental para tahanan. Televisi CBS Amerika juga menayangkan seorang tawanan yang mengaku ditelanjangi dan diancam diperkosa, sementara tangan dan kakinya dirantai dan kepalanya ditutupi kain. Banyak juga tahanan dipaksa minum air hingga muntah darah. Beberapa tahanan lainnya mengatakan mereka diperkosa, dipukuli, setelah itu dibiarkan dalam keadaan telanjang selama beberapa hari. ${ }^{7}$ Adapun teknikteknik interogasi sipir militer AS dalam penjara Guantanamo dan di penjara Abu Ghraib meliputi: ${ }^{8}$

1. Isolation. Tahanan ditinggalkan atau diisolasi di sebuah ruangan khusus isolasi, sampai ia mengalami kegelisahan dan timbul keinginan yang sangat besar untuk berinteraksi.

2. Sleep Deprivation. Tahanan disiksa dengan cara dilarang tidur selama beberapa hari. Jika sudah sampai di hari tertentu, tahanan akhirnya dibolehkan tidur, tetapi waktunya sangat sebentar dan langsung dibangunkan lagi. Hal tersebut bisa membuat tahanan sangat pusing dan membuat pandangannya kabur. Apalagi selama menjalani masa pemaksaan tidak tidur, porsi makanan tahanan sangat dibatasi.

3. Sensory Deprivation. Tempat semacam tabung yang dibuat khusus untuk tahanan dalam menjalani siksaan agar mau berbicara. Tabung tersebut hanya diberi 
lubang untuk bernafas. Selama didalam tabung, tahanan akan mengalami depresi yang sangat berat dan akan dikeluarkan jika ia mau berbicara.

4. Stress Position. Tahanan dipaksa untuk berdiri selama berjam-jam. Selain itu, banyak metode lain yang menjadi tambahan untuk penyiksaan jenis ini. Salah satunya adalah berdiri tanpa pegangan dan kedua lengan harus diangkat.

5. Sensory Bombardment. Tahanan ditaruh dalam suatu ruangan lalu diberi cahaya yang amat silau dan suara-suara yang keras, membuat tahanan mengalami gangguan pada berbagai inderanya dan bisa kehilangan konsenterasi.

6. Forced Nudity. Para tahananan dikumpulkan lalu dipanggil salah satu dari mereka dan ditelanjangi. Tahanan yang telanjang diinterogasi dan akan diperbolehkan berpakaian lagi jika interogasi berjalan lancar. Namun jika tidak, tahanan akan diancam dengan siksaan-siksaan lainnya.

7. Sexual Humiliation. Para tahanan dipaksa berhubungan seks sesama jenis, menari striptis dan penyiksaan-penyiksaan seksual lainnya yang dilakukan tentara Amerika agar para tahanan mau menjawab segala pertanyaan yang mereka tanyakan.

8. Cultural Humiliation. Penghinaan verbal, pemaksaan makan babi atau makan makanan haram lainnya bagi tahanan Muslim.
9. Extreme Cold atau Hot Box. Extreme Cold adalah jenis penyiksaan yang menggunakan bantuan alam atau alat yang bisa membuat tahanan merasa sangat kedinginan. Sedangkan Hot Box adalah jenis penyiksaan yang akan membuat tahanan merasa sangat kepanasan.

10. Phobias. Dikurung bersama sesuatu yang tahanan takuti, seperti laba-laba, kalajengking, bahkan ular dan beberapa hewan atau benda lainnya, agar tahanan mengalami rasa panik dan takut yang luar biasa.

11. Waterboarding. Metode ini belakangan dilarang digunakan dalam kemiliteran AS. Waterboarding dilakukan dengan mengikat tubuh tahanan pada sebuah papan atau meja dengan posisi kaki lebih tinggi daripada kepala, lalu matanya ditutup. Kemudian wajah tahanan disiram dengan air berulang kali dengan teknik tertentu. Secara psikolog tahanan akan merasa dirinya tenggelam dan timbul reaksi tersedak karena air yang diguyurkan ke wajahnya itu. Metode ini sangat efektif karena dalam percobaan yang dilakukan terhadap anggota CIA sendiri, ternyata rata-rata mereka hanya bertahan selama 14 detik.

Dugaan perlakuan tidak berprikemanusiaan terhadap tawanan perang dalam penjara Guantanamo maupun di penjara Abu Ghraib oleh oknum sipir militer AS mengindikasikan: Adanya perbedaan penafsiran terhadap prinsip-prinsip dasar dan pasal-pasal dalam hukum humaniter 
internasional; Sulitnya membedakan antara kombatan dan penduduk sipil dalam perang modern saat ini; Adanya perkembangan bentuk konflik yang tadinya hanya konflik bersenjata internasional kemudian muncul konflik bersenjata non internasional; Adanya perbedaan norma antara Protokol Tambahan I tahun 1977 dan Protokol Tambahan II tahun 1977. Oleh karena itu, adanya indikasi perbedaan penafsiran terhadap pasal-pasal dalam hukum humaniter internasional berimplikasi terhadap pengimplementasian hukum humaniter internasional oleh Negara-negara peratifikasi.

\section{PENUTUP}

\section{Simpulan}

Konsep perlindungan hukum terhadap tawanan perang dalam Konvensi Jenewa III tahun 1949 menunjukkan bahwa kombatan yang telah berstatus 'Hors de combat' harus dilindungi dan dihormati dalam segala keadaan. Penghormatan berupa kewajiban untuk tidak melakukan tindakantindakan yang membahayakan, tidak memperparah keadaan, dan tidak membunuh orang yang dilindungi. Negara penahanpun berkewajiban untuk mencegah bahaya dan kerusakan.

Implementasi Konvensi Jenewa III Tahun 1949 terhadap tawanan perang Amerika Serikat di penjara Guantanamo belum optimal. Hal tersebut terjadi karena adanya perbedaan penafsiran terhadap Pasal-Pasal dalam Hukum Humaniter Internasional sehingga berakibat adanya indikasi praktek-praktek perlakuan tidak manusiawi, tidak mendapat perlindungan hukum, tidak diperhatikan kesejahteraannya dan tidak berhubungan dengan dunia luar di Penjara Guantanamo yang di lakukan oleh sipir militer Amerika Serikat.

\section{Saran}

Agar Pemerintah Indonesia melalui kementerian luar negeri menyuarakan penutupan penjara guantano. Agar pemerintah Indonesia melalui forum ASEAN mengajak Negara-negara Asia Tenggara membentuk lembaga peradilan HAM ASEAN untuk mengadili penjahat kemanusiaan.

\section{DAFTAR PUSTAKA}

Buku

Kosasi, Ahmad. HAM Dalam Perspektif Islam, Salemba Diniyah. Jakarta. 2003.

Muhammad Jamal, Ahmad. Perang, Damai dan Militer Dalam Islam. Fikahati Aneska. Jakarta. 1991.

Permanasari, Arlina, et.al. Pengantar hukum humaniter. ICRC. Jakarta. 1999.

H. Georges. Aldrich. Prospects for United States Ratifi cation of Additional Protocol I to the 1949 Geneva Conventions. 1991.

Igor, Primoratz (ed), Civilian Immunity in War. New York: Oxford University Press. 2007.

Pictet, Jean. Development and Principles of Internasional Humanitarian Law. Martinus Nicholf Publisher. 1985.

Elwina S. Marcella. Mengatur Kejahatan Perang, Tampa Penerbit. Karawang. 2004.

Pomerance, Michla. Self Determination in Law And Practice: The New Doctrine of the United Nations. The Hague/Boston: M. Nijhoff. 1982.

Atmasasmita, Romli. Terjemahan Konvensi Jenewa Tahun 1949. Departemen Kehakiman. Jakarta. 1999.

Davidson, Scott. Hak Asasi Manusia (Sejarah, Teori dan Praktek Dalam Pergaulan Internasional). Penerjemah; A.Hadyana Pudjaatmaka. Pustaka Utama Grafiti. 1994. 


\section{Makalah}

Asia Week, Pelanggaran HAM di Aceh, Dokumentasi CSIS, Edisi 4 April 1991

Media Indonesia, Penyiksaan Tawanan Perang Amerika dan Inggris sangat menjijikkan Edisi Maret 2004.

M.M. Billah, Tipologi dan Praktek Pelanggaran Hak Asasi Manusia di Indonesia, Makalah seminar pembangunan nasional VII, Badan pembinaan hukum nasional DEPKEH dan HAM, Denpasar, 14-18 Juli 2003 